\title{
E-era (Digital Economy) Impact on Consumer Electronic Purchase Intention-A Pragmatic Analysis of Pakistani Consumer with Integration of TAM and TPB with Perceived Risk, Perceived Credibility and Perceived Benefit
}

\author{
Zartasha Khalid and Mehrukh Salman
}

\begin{abstract}
Over the past few decades, scholars have widely used Technology Acceptance Model (TAM) and Theory of Planned Behaviors (TPB) in order to examine IT usage and E-services acceptance. But, neither TAM nor TPB have been able to provide consistent explanation or behavioral prediction of consumers. The aim of this research is to check what difference in our culture has been formed due to the implications of theory of planned behavior and technology acceptance model in digital economy. The sample size was 328 respondents. The results showed that attitude fully mediates the relationship between electronic behavioral intention and perceived usefulness. It is suggested that the future research on antecedents of Behavioral Intention should be studied with respect to the Pakistani culture.
\end{abstract}

Index Terms-Perceived credibility, perceived risk, TAM model and TPB model.

\section{INTRODUCTION}

Over the past few decades, scholars have widely used Technology Acceptance Model (TAM) and Theory of Planned Behavior (TPB) in order to examine IT usage and E-services acceptance (Davis, 1989) [1]. But, neither TAM nor TPB have been able to provide consistent explanation or behavioral prediction of consumers (Cheng et al., 2006) [2]. Recent trend in economy showed that online shopping is increasing constantly, and retail sales showed a growth from $\$ 172$ in 2005 till \$329 Billion in 2010. From the rise of using internet, different scholars began predicting the shift in economy from marketer to the consumers, further suggesting a new form of customer relationship management (Igbaria et al., 1996; Pikkarainen et al., 2004; Ramayah \& Ignatius,2005; Zhu \& Chan, 2014) [3]-[6].

The advancement in technology has highly populated the internet worldwide, where there are approximately 2000 million users on daily basis (Internet World Statistics, 2011). With all this traffic on the internet, many companies are shifting their focus on establishing online selling channels

Manuscript acceptance April 16, 2018; revised July 12, 2018. This work was self-supported at Lahore School of Economics. The research paper is "E-era (Digital Economy) Impact on Consumer Electronic Purchase Intention-A Pragmatic Analysis of Pakistani Consumer with Integration of TAM and TPB with Perceived Risk, Perceived Credibility and Perceived Benefit"

Zartasha Khalid is with Coca Cola, Pakistan (e-mail:khalidzartasha@gmail.com).

Mehrukh Salman is with Lahore School of Economics, Pakistan (e-mail: mehrukh.jawaid@gmail.com). and introducing products over online stores. The online channels propose time and cost-effective methods of promoting products in a far better way thus enabling to build strong customer relationship (Kaleem \& Ahmed, 2008; Kallamarthodi \& Vaithiyanathan, 2001; Lee,2008) [7]-[9].

The Theory of Planned Behavior is aimed to study attitudes and behaviors of consumers towards technology acceptance model. This aggregation will help marketers to understand consumer's behavior or human behavior. In fact, it is argued that attitudes and personality of humans have an impact on specific behaviors (Ajzen 1991; Fishbein \& Ajzen, 1975) [10], [11].

The theory of planned behavior was proposed by Ajzen (1991) [10]. He explained how an individual behavior can predict one's intention; intention was predicted by attitudes towards behavior and lastly subjective norms covering the performance of the behavior "the perceived social pressure to perform or not to perform the behavior" (Ajzen, 1991) [10]. Whereas, perceived control behavior (PCB) is explained as an individual's perception of controlling their behavior. In other words, PCB refers to the "people's perception of ease or difficulty in performing the behavior of interest" (Ajzen, 1991) [10].

Davis (1989) [1], proposed the Technology Acceptance Model (TAM), which is proved to be the most useful model for studying the innovation in technology (Bagozzi et al., 1992) [12]. TAM has been used in variety of researches to explore the factors affecting an individual use of technology in modern era (Davis \& Venkatesh, 1996) [13].

The aim of this research is to check what difference in our culture has been formed due to the implications of theory of planned behavior and technology acceptance model in digital economy and also to explore the extent of theory of planned behavior predictors and technology acceptance model with consumer purchase intentions with the integration of perceived risk, perceived creditability and perceived benefits in it.

\section{LITERATURE REVIEW}

The theory of planned behavior was proposed by Ajzen (1991) [10]. He explained how an individual behavior can predict one's intention; intention was predicted by attitudes towards behavior and lastly subjective norms covering the performance of the behavior "the perceived social pressure to perform or not to perform the behavior" (Ajzen, 1991) [10]. 
Theory of Technology Acceptance Model (TAM) states that an individual's perceptions about ease of use and perceived usefulness are the main two cognitive factors that determine one's acceptance towards technology system. Over the years TAM have received quite empirical support in amplification of consumer acceptance of various types of technological advancements e.g. services based on technology, the new media and smart phones (Zhu \& Chan, 2014) [6]. Over the past few years, TAM model is constantly showing advancements. It was proposed by (Davis, 1989) [1] and replicated by (Venkatesh \& Bala, 2008) [14].

Different studies tried to show the relationship between TAM and TRA but some failed to do so and the difference has been evident among these two theories. (Davis, 1989) [1] compared both TRA and TAM on MBA student's relative facility with a word processor across two time periods, which was immediately introduced 14 weeks later. The results showed that TAM was better in explaining the acceptance intention of the users as compared to TRA. Then, TRA and TAM were compared and showed that TAM offered empirical advantage and is simpler to use as compared to TAM.

Consumers are very reluctant when they feel risk is involved in certain purchasing of products or if they feel any action may cause uncertain consequences (Beatty et al., 2001) [15]. (Williams \& Anderson, 1991) [16], suggested that perceived risk is a powerful factor while explaining consumer behavior in both traditional and online environments. He explained that consumers are more motivated to avoid risk than to maximize utility to purchase. Different researchers agree on the fact that the existence of different dimensions consisting of perceived risk construct, both in the traditional context and in the online environment (Bagozzi et al., 1992) [12]. Trust has played a significant role in influencing consumers' intention to use internet services such as internet bank (Al-Ajam \& Noor, 2013; Colakoglu et al., 2010; Muhammad et al., 2012; Wiener, 1982) [17]-[20].

The element of trust in any object or person is primarily built on repeated encounter through channels of social network and as satisfaction increases it becomes stronger (Beatty et al., 2001) [15]. Various researches and theories define the element of trust, for instance the information-system suggests that based on trusting beliefs, the users expect a positive result regarding a product (Chau et al., 2003) [21]. According to (Phillips et al., 1994) [22]; the trust factor mainly enables the individual to perform and survive in ambiguous environments and enables to reduce the perceived risk. As in online stores scenario the consumer may or may not be disappointed by the merchandise when delivered and not as per expectation as portrayed through online advertisements. Perceived ease of use has been added to technology adoption theory (TAM), which resulted in poor user interface design and was related to IT rejection (Venkatesh \& Bala, 2008) [14].

Attitude was acting as a mediator between perceived ease of use and behavioral intention, also with perceived usefulness and electronic behavioral intention (Davis, 1989) [1] but recent research showed that attitude was excluded from the model, because it was showing a weaker relationship between the constructs (Guriting et al., 2006; Yi
\& Hwang, 2003) [23], [24]. Hosein, (2009) [25] studied The Importance of Perceived Benefits in Intentions to Use Internet Banking among Greek PC Users. The results indicated that perceived benefit had a significant impact on intention to use online banking services.

Perceived Credibility is important because security, privacy, and trust issues are common concern of online service users around the world (Hosein, 2009) [25]. Consumers avoid online services due to lack of credibility (Lee, 2008) [9]. Perceived credibility has a significant effect on the intention to use online services (Morris \& Venkatesh, 2000) [26].

(Fishbein, 1975) [11] states that attitude represent one's learned tendency to act consistently towards a behavior. They have been authenticating as a strong antecedent of behavioral intentions in a variety of technology adoption contexts for instance in hospitality. (Wu and Wang, 2005) [27] results showed that attitude had a weaker relationship with electronic behavioral intention and was excluded from the model.

\section{MethodolOGY}

\section{A. Research Philosophy}

Positivist approach was used for explaining research philosophy. Positivist approach is based on knowledge or facts derived from positive verifications of experiences rather than based on intuitions. Data collection was done through logical reasoning, experience and mathematical tests. It is heavily dependent on experimental and indirect methods.

\section{B. Research Approach}

The research approach was based on deductive reasoning. (Wofford \& Laurie, 1993) [28] suggested that "positivist research is more biased when deductive approach is used in study".

\section{Research Strategy}

The research strategy was based on questionnaires, regarding the dependent, mediating and independent variables. (Wofford \& Laurie, 1993) [28] investigated that surveys are always done on extensive number of populations. Questionnaires are cost-effectives mode of data collection.

\section{Sample Size and Data Collection}

The ratio of male $(57.6 \%)$ was higher than the females $(42.4 \%)$ as in Pakistan the males are using internet more than females. The highest population of the sample using internet $(84.1 \%)$ had age between $20-30$ years, while $(8.5 \%)$ of the population had age bracket of 31-40 years, whereas $(9 \%)$ were in the age bracket of 41 -above and only (6.4\%) were in the age bracket of Below 20 years

\section{REsUlTS}

\section{A. Measurement Analysis}

Structural Equation Modeling (SEM) was employed for the measurement of the model used in this study. SEM consists of two types of models. First one is the measurement 
model that checks the validity of model in three steps uni-dimenionality, reliability and validity whereas second one is the structural model. Before proceeding to the structural model latent construct used for the measurement should be valid (Yusoff et al., 2009) [29].

All variables under study showed reliability above 0.7 .

\section{B. Direct Effects}

Hypothesis indicated that perceived usefulness (PU) has a significant impact with electronic behavioral intention (BI) i.e. we accept Hypothesis $1(\mathrm{r}=0.573, \mathrm{p}<0.05$ i.e. highly significant $* * *$, respectively). Perceived usefulness has a significant positive relation with electronic behavioral intention (BI).

Hypothesis indicated that perceived risk has a significant relationship with electronic behavioral intention (BI) i.e. we accept Hypothesis $2(r=0.573, p<0.05$ i.e. highly significant 0.028 , respectively). Perceived risk has a significant positive relation with electronic behavioral intention (BI).

Hypothesis indicated that perceived trust has no significant relationship with electronic behavioral intention (BI) i.e. it shows hypothesis 3 was rejected $(r=0.573, p>0.05$ i.e. not significant 0.196 , respectively). Perceived trust has no significant positive relation with electronic behavioral intention $(\mathrm{BI})$.

Hypothesis indicated that perceived credibility has a significant relationship with electronic behavioral intention (BI) i.e. we accept Hypothesis $4(\mathrm{r}=0.573, \mathrm{p}<0.05$ i.e. highly significant 0.014 , respectively). Perceived credibility has a significant positive relation with electronic behavioral intention (BI).

Hypothesis indicated that perceived usefulness has a significant relationship with electronic behavioral intention (BI) i.e. we accept Hypothesis 5 ( $\mathrm{r}=0.573, \mathrm{p}<0.05$ i.e. highly significant $* * *$, respectively). Perceived usefulness has a significant positive relation with electronic behavioral intention (BI).

Hypothesis indicated that subjective norm has no significant relationship with electronic behavioral intention (BI) i.e. it shows hypothesis 6 was rejected $(r=0.573, p>$ 0.05 i.e. not significant 0.573 , respectively). Subjective norm has no significant positive relation with electronic behavioral intention (BI).

Hypothesis indicated that perceived benefit has no significant relationship with electronic behavioral intention (BI) i.e. it shows hypothesis 7 was rejected $(r=0.573, p>$ 0.05 i.e. not significant 0.270 , respectively). Perceived benefit has no significant positive relation with electronic behavioral intention (BI).

Hypothesis indicated that attitude has a significant relationship with electronic behavioral intention (BI) i.e. we accept Hypothesis $8(\mathrm{r}=0.573, \mathrm{p}<0.05$ i.e. highly significant $* * *$, respectively). Attitude has a significant positive relation with electronic behavioral intention (BI).

The model fit of the hypothesis testing showed that the Comparative Fit Index (CFI) is 0.708 and Incremental Fit Index (IFI) is 0.710 . All these parameters should always be > 0.7 to have a perfect model fit (Muhammad et al., 2012) [19]. The Chi-square of this model was 2880.505. The RMSEA for this model is 0.10 . Different author stated that Root Mean
Square Error of Approximation (RMSEA) has a cut-off less than 0.10 is accepted (Davis, 1989) [1].

\section{Total and Indirect Effects}

Attitude is fully mediating the relationship between perceived usefulness and electronic behavioral intention i.e. when indirect is significant and direct is insignificant it shows full mediation between the variables. Therefore, we accept the hypothesis i.e. Attitude fully act as a mediator between perceived usefulness and electronic behavioral intention (BI).

The baseline comparison for mediation model showed that all values were above 0.80 . The model fit of the hypothesis testing showed that the Comparative Fit Index (CFI) was 0.876 and Incremental Fit Index (IFI) is 0.877. All these parameters should always be $>0.7$ to have a perfect model fit (Muhammad et al., 2013) [19].

There is no mediation found between perceived ease of use and electronic behavioral intention of consumers i.e. when indirect is insignificant and direct is insignificant it showed no mediation between the variables. So, we reject the hypothesis i.e. Attitude does not act as a mediator between perceived ease of use and electronic behavioral intention (BI).

\section{Discussions AND CONCLUSION}

The results showed that perceived usefulness has a significant impact with electronic behavioral intention (BI) of consumers. Different researchers suggest that perceived usefulness is the subjective possibility that using certain technology would develop the way a user could comprehend a given task.

Perceived trust has no significant relationship with electronic behavioral intention (BI). Individual's reliance on another party under conditions of dependence and risk. (Currall and Judge, 1995) [30]. Perceived Credibility has a significant relationship with electronic behavioral intention (BI).

Perceived ease of use has a significant relationship with electronic behavioral intention (BI). Perceived ease of use is defined as "the extent to which a user believes that using a technology to complete a task is effort-free" (Davis, 1989) [1]. (Lee, 2008) [9] studied TAM and TRA with an integration of perceived risk and perceived benefit to understand consumer online intention in the banking sector. The results indicated that intention to use was positively affected by perceived benefit, attitude and perceived ease of use. Subjective norm has no significant relationship with electronic behavioral intention (BI). According to (Ajzen, 1991) [10] the subjective norm being a part of the overall framework of Theory of Planned Behavior (TPB), is defined as the social pressure perceived by an individual which drives his/her decision to perform or not to perform a specific behavior.

Perceived benefit has no significant relationship with electronic behavioral intention (BI). (Sheth, 1983) [31], "postulated that personal determinants of shopping in traditional formats can be broadly understood as being influenced by functional and nonfunctional motives". 
Attitude has a significant relationship with electronic behavioral intention (BI). (Lee, 2008) [9] studied TAM and TRA with an integration of perceived risk and perceived benefit to understand consumer online intention in the banking sector. The results indicated that intention to use was positively affected by perceived benefit, attitude and perceived usefulness.

Perceived risk has a significant relationship with electronic behavioral intention (BI). Consumers are very reluctant when they feel risk is involved in certain purchasing of products or if they feel any action may cause uncertain consequences. The possibility of the product malfunctioning and not performing as it was designed and advertised and therefore failing to deliver the desired benefits (Lee, 2008) [9].

\section{RECOMMENDATIONS}

The study finding and major contribution of this current study must be appraised by taking into considerations the major limitation during this research. If more time could be available a longitudinal study would be preferred for this frame work in order to study effects of each variable in depth.

Another major limitation was geographical constraint i.e. data was gathered from Lahore region only. The entire Pakistan cannot become a part of this study since gathering data is costly and time consuming. For future purpose similar frame work can be applied to other cities of Pakistan in order to attain the overall view of the study.

It is suggested that the future research on antecedents of Behavioral Intention should be studied with respect to the Pakistani culture. Future study can be done on more antecedents of Behavioral Intention i.e. Perceived behavioral control, social impact, fashion trends and technology trends.

\section{CONFLICT OF INTEREST}

The authors declare no conflict of interest.

\section{AUTHOR CONTRIBUTIONS}

Zartasha Khalid, selected the topic and wrote the paper Mehrukh Salman analyzed the data, reviewed the paper in detail; all authors had approved the final version.

\section{REFERENCES}

[1] F. D. Davis, "Perceived usefulness, perceived ease of use, and user acceptance of information technology," MIS Quarterly, vol. 13, no. 3, pp. 319-339, 1989

[2] T. Cheng, D. Lama, and A. Yeung, "Adoption of internet banking: An empirical study in Hong Kong," Decision Support Systems, vol. 42, no. 3, pp. 1558-1572, 2006.

[3] M. Igbaria, S. Parasuraman, and J. J. Baroudi, "A motivational model of microcomputer usage," Journal of Management Information Systems, vol. 13, no. 1, pp. 127-143, 1996.

[4] T. Pikkarainen, K. Pikkarainen, H. Karjaluoto, and S. Pahnila, "Consumer acceptance of online banking: An extension of the technology acceptance model," Internet Research, vol. 14, no. 3, pp. 224-235, 2004.

[5] T. Ramayah and J. Ignatius, "Impact of perceived usefulness, perceived ease of use and perceived enjoyment on intention to shop online,' ICFAI Journal of Systems Management (IJSM), vol. 3, pp. 36-51, 2005.

[6] D. Zhu and Y. Chan, "Investigating consumer attitude and intention towards free trails of technology-based services," Computers in Human Behavior, vol. 34, pp. 328-334, 2014.
[7] A. Kaleem and S. Ahmad, "Bankers perceptions of electronic banking in Pakistan," Journal of Internet Banking and Commerce, 2008.

[8] Kallamarthodi and Vaithiyanathan, "Assessment of a modified technology acceptance model among e-banking customers in Coimbatore city," International Journal of Innovation, Management and Technology, vol. 3, no. 2, pp. 181-187, 2011.

[9] M. C. Lee, Factors Influencing the Adoption of Internet Banking: An Integration Case, 2008.

[10] I. Ajzen, "The theory of planned behavior," Organ Behavior Human Decision Procedure, vol. 50, no. 2. pp. 121-79, 1991

[11] M. Fishbein and I. Ajzen, Belief, Intention and Behavior: An Introduction to Theory and Research, Addison Wesley, 1975.

[12] R. P. Bagozzi, F. D. Davis, and P. R. Warshaw, "Development and test of a theory of technological learning and usage," Human Relations, vol. 45, no. 7, 1992.

[13] F. F. Davis and V. Venkatesh, A Critical Assessment of Potential Measurement, 1996.

[14] V. Venkatesh and H. Bala, "Technology acceptance model 3 and a research agenda on interventions," Decision Science, vol. 39, no. 2, pp. 273-312, 2008.

[15] R. C. Beatty, J. P. Hsim, and M. C. Jones, "Factors influencing corporate web site adoption: A time-based assessment," Information and Management, vol. 3, no. 6, pp. 337- 354, 2001.

[16] L. Williams and S. Anderson, "Job satisfaction and organizational commitment as predictors of organizational citizenship and in-role behaviors," Journal of Management, vol. 17, pp. 601-617, 1991.

[17] A. Al-Ajam and N. K. M. Sand, "Influencing factors on behavioral intention to adopt internet banking service," World Applied Sciences Journal, vol. 22, pp. 1652-1656, 2013.

[18] U. Colakoglu, O. Culha, and H. Atay, "The effects of perceived organizational support on employees' affective outcomes: Evidence from the hotel industry," Tourism and Hospitality Management, vol. 16, no. 2, pp. 125-150, 2010.

[19] F. Muhammad, M. Y. M. Hussin, and A. A. Razak, "Automobile sales and macroeconomic variables: A pooled mean group analysis for Asian countries," Journal of Business and Management, vol. 2, no. 1, pp. 15-21, 2012.

[20] Y. Wiener, "Commitment in organizations: A normative view," Academy of Management Review, vol. 7, pp. 418-428, 1982.

[21] P. Y. K. Chau and V. S. K. Lai, "An empirical investigation of the determinants of use acceptance of Internet banking," Journal of Organizational Computing and Electronic Commerce, vol. 13, no. 2 , pp. 123-145, 2003.

[22] L. A. Phillips, R. Calantone, and M. Lee, "International technology adoption: Behavior structure, demand certainty and culture," Journal of Business and Industrial Marketing, vol. 9, no. 2, pp. 16-28, 1994.

[23] P. Guriting and O. N. Nelson., "Borneo online banking: Evaluating customer perceptions and behavioral intention," Management Research News, vol. 29, no. 1/2, pp. 6-15, 2006.

[24] M. Yi and Y. Hwang, "Predicting the use of web-based information systems: Self-efficacy, enjoyment, learning goal orientation, and the technology acceptance model," International Journal of Human e-Computer Studies, vol. 59, no. 4, pp. 431-449, 2003.

[25] N. Z. Hosein, "Internet banking: An empirical study of adoption rates among Midwest community banks," Journal of Business \& Economics Research, vol. 7, no. 11, p. 51, 2009.

[26] M. G. Morris and V. Venkatesh, "Age-differences in technology adoption decisions - Implications for a changing work-force," Personnel Psychology, vol. 53, no. 2, pp. 375- 403, 2000.

[27] J. Wu and S. Wang, "What drives mobile commerce? An empirical evaluation of the revised technology acceptance model," Information Management, vol. 42, no. 5, pp. 719-729, 2005.

[28] J. Wofford and Z. L. Laurie, "Path-goal theories of leadership: A meta-analysis," Journal of Management, vol. 19, no. 4, pp. 857-876, 1993.

[29] Y. M. Yusoff, Z. Muhammad, E. S. E. Pasah, and E. Robert, "Individual differences, perceived ease of use, and perceived usefulness in the e-library usage," Computer and Information Science, vol. 2, no. 1, pp. 76-83, 2009.

[30] S. Currall and T. Judge, "Measuring trust between organizational boundary role persons," Organizational Behavior and Human Decision Processes, vol. 64, pp. 151-170, 1995.

[31] J. N. Sheth, "An integrative theory of patronage preference and behavior," in W. R. Darden and R. F. Lusch, Eds. Patronage Behavior and Retail Management, Orlando, FL: Elsevier, 1983, pp. 9-28.

Copyright (C) 2020 by the authors. This is an open access article distributed under the Creative Commons Attribution License which permits unrestricted 
use, distribution, and reproduction in any medium, provided the original work is properly cited (CC BY 4.0).

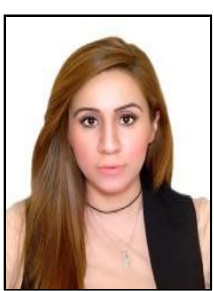

Zartasha Khalid is a graduate of Lahore School of Economics. She did her master's in business administration (MBA) in marketing in 2017 and bachelor's in business administration (BBA) with double majors in marketing and finance (2015) from Lahore School of Economics, Pakistan.

She is working with Coca Cola Pakistan from 2017.

Her current role is Group Incident Management Crisis Resolution (IMCR) manager, in Pakistan. Her role requires looking after Central Asia, Turkey, Jordon and Iraq.
Mehrukh Salman is an assistant professor at Lahore School of Economics. She has an experience of over 10 years in teaching undergraduate and post graduate students. She is an MPhil and completed her pos graduate diploma in research. Currently she is a permanent faculty of Lahore School of Economics. 